\title{
In Vitro Synaptogenesis between the Somata of Identified Lymnaea Neurons Requires Protein Synthesis But Not Extrinsic Growth Factors or Substrate Adhesion Molecules
}

\author{
Zhong-Ping Feng, ${ }^{1}$ Judith Klumperman,, ${ }^{2}$ Ken Lukowiak, ${ }^{1}$ and Naweed I. Syed ${ }^{1}$ \\ ${ }^{1}$ Respiratory and Neuroscience Research Groups, Departments of Anatomy and Medical Physiology, Faculty of Medicine, \\ University of Calgary, Calgary, Alberta, Canada T2N 4N1, and 2Faculty of Biology, Free University Amsterdam, \\ The Netherlands
}

Nerve growth factors, substrate and cell adhesion molecules, and protein synthesis are considered necessary for most developmental programs, including cell proliferation, migration, differentiation, axogenesis, pathfinding, and synaptic plasticity. Their direct involvement in synapse formation, however, has not yet been fully determined. The neurite outgrowth that precedes synaptogenesis is contingent on protein synthesis, the availability of externally supplied growth factors, and substrate adhesion molecules. It is therefore difficult to ascertain whether these factors are also needed for synapse formation. To examine this issue directly we reconstructed synapses between the cell somata of identified Lymnaea neurons. We show that when paired in the presence of brain conditioned medium (CM), mutual inhibitory chemical synapses between neurons right pedal dorsal 1 (RPeD1) and visceral dorsal 4 (VD4) formed in a soma-soma configuration ( $86 \% ; n=50)$. These synapses were reliable and target cell specific and were similar to those seen in the intact brain. To test whether synapse formation between RPeD1 and VD4 required de novo protein synthesis, the cells were paired in the presence of anisomycin (a nonspecific protein synthesis blocker). Chronic anisomycin treatment (18 hr) after cell pairing completely blocked synaptogenesis between RPeD1 and VD4 ( $n=24)$; however, it did not affect neuronal excitability or responsiveness to exogenously applied transmitters $(n=7)$, nor did chronic anisomycin treatment affect synaptic transmission between pairs of cells that had formed synapses $(n=5)$. To test the growth and substrate dependence of synapse formation, RPeD1 and VD4 were paired in the absence of CM [defined medium; $(n=22)$ ] on either plain plastic culture dishes $(n=10)$ or glass coverslips $(n=10)$. Neither CM nor any exogenous substrate was required for synapse formation. In summary, our data provide direct evidence that synaptogenesis in this system requires specific, cell contact-induced, de novo protein synthesis but does not depend on extrinsic growth factors or substrate adhesion molecules.

Key words: synapse formation; in vitro; growth factors; Lymnaea; soma-soma synapses; mollusks
To function properly, the adult brain relies heavily on neuronal connectivity patterns that are orchestrated during early embryonic development (McMahan, 1990; Nelson et al., 1990; Goodman and Shatz, 1993; Hall and Sanes, 1993; Jessel and Kandel, 1993; Goodman, 1994, 1996; Grantyn et al., 1995; Katz and Shatz, 1996; Wu et al., 1996; Spencer et al., 1997). Yet, the cellular and molecular mechanisms (intrinsic and/or extrinsic) that determine the specificity of synaptic connections in the nervous system remain poorly understood. This gap in our fundamental knowledge regarding nervous system development (and also regeneration) owes its existence to the complexity of the mammalian brain: synapse formation between defined pre- and postsynaptic neurons can be studied only rarely in the intact nervous system. Various in vivo and in vitro preparations have helped to identify

\footnotetext{
Received June 26, 1997; revised July 18, 1997; accepted July 28, 1997.

This work was supported by the Medical Research Council (MRC) (Canada). Z.-P.F. is supported by an MRC-Alberta Lung Association studentship. N.I.S. is an Alberta Heritage Foundation for Medical Research scholar, an Alfred P. Sloan Fellow, and a Parker B. Francis Fellow. We thank Dr. R. B. Hawkes for his critical comments on an earlier draft of this manuscript. Excellent technical support by $\mathrm{Mr}$. Wali Zaidi is also acknowledged.

Correspondence should be addressed to Dr. Naweed I. Syed, Department of Anatomy, Faculty of Medicine, University of Calgary, Calgary, Alberta, Canada, T2N 4N1.

Dr. Klumperman's present address: Medical School, University of Utrecht, AZU, Room H02.314 Heidelberglaan 100, 3584CX Utrecht, The Netherlands.

Copyright (C) 1997 Society for Neuroscience $0270-6474 / 97 / 177839-11 \$ 05.00 / 0$
}

extrinsic environmental factors that regulate neurite outgrowth, axonal pathfinding, target cell selection, synapse specificity, and modulation (Glanzman et al., 1989; Taira et al., 1993; Bonhoeffer, 1996). In most systems studied thus far, growth factors (Lindsay et al., 1994; Funakoshi et al., 1995; Braun et al., 1996; Cellerino and Maffei, 1996; Henderson, 1996; Lewin, 1996), protein synthesis (Ambron et al., 1985; Steward et al., 1988), and substrate adhesion molecules (Doherty and Walsh, 1989) are considered necessary requirements for neurite outgrowth (Fujii et al., 1982; Chiquet and Nicholls, 1987; Bulloch and Syed, 1992). Whether synaptogenesis is also contingent on these factors has not yet been fully determined. The answer is difficult to discover in most preparations, because synapse formation requires neurite extension, which in turn relies on the availability of various growth factors (Henderson, 1996) and substrate adhesion molecules (Doherty and Walsh, 1989) as well as on newly synthesized proteins (Steward et al., 1988).

To obtain synapses in the absence of neurite outgrowth, Fuchs et al. $(1981,1992)$ developed soma-soma synapses between the identified leech neurons. Haydon (1988) subsequently adopted this approach to develop and exploit soma-soma synapses between the identified Helisoma neurons. This approach was further extended to leech (Nicholls et al., 1990) and Aplysia (Klein, 1994), in which appropriate synapses between the cell somata of identified neurons were successfully reconstructed in the absence 


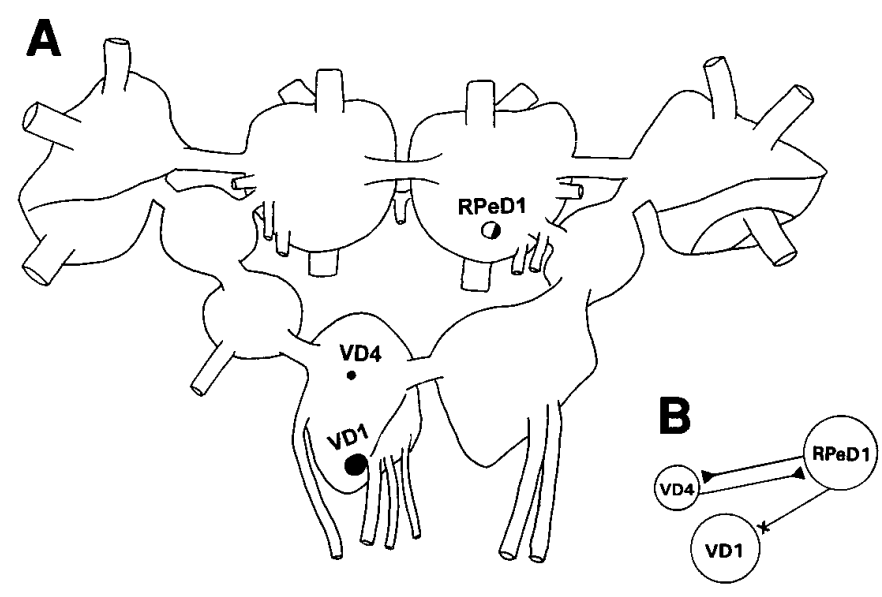

Figure 1. Diagram showing the position, location, and nature of synaptic connections between the neurons used in the present study. $A$, Schematic diagram showing the location of identified neurons, right pedal dorsal 1 (RPeD1) and visceral dorsal 4 (VD4) and 1 (VD1), located in the right pedal and visceral ganglia, respectively. $B$, Diagram depicting the nature of in vivo synaptic connections between the neurons. RPeD1 and VD4 have mutual inhibitory connections (closed symbols), whereas RPeD1 does not synapse with VD1 $(X)$.

of neurite outgrowth. This soma-soma synapse approach has led to a greater understanding of intrinsic ionic and synaptic mechanisms that regulate synaptogenesis and synaptic function (Nicholls et al., 1990; Haydon and Drapeau, 1995). Under these experimental conditions, however, both extrinsic trophic molecules [conditioned medium (CM), Helisoma: (Haydon, 1988); hemolymph, Aplysia (Klein, 1994); fetal serum, leech (Nicholls et al., 1990)] and various substrate molecules [poly-L-lysine, Helisoma (Haydon, 1988); no substrate, Aplysia (Klein, 1994); concanavalin A, leech (Nicholls et al., 1990)] were considered necessary for either neurite outgrowth or soma-soma synapses to form. Finally, whether the specificity of synaptogenesis between the soma-soma paired neurons required newly synthesized proteins was not fully tested.

To examine some of the above issues, we tested the following hypotheses: (1) specific synapses between the cell somata of identified Lymnaea neurons reform in a soma-soma configuration, and (2) synaptogenesis between the somata pairs is contingent on de novo protein synthesis, which is intrinsically regulated, and does not require extrinsic trophic factors and foreign substrate adhesion molecules. To test these hypotheses, we first developed an in vitro model system in which reciprocal inhibitory synapses between the somata of identified Lymnaea respiratory neurons right pedal dorsal 1 (RPeD1) and visceral dorsal 4 (VD4) were reconstructed in cell culture. RPeD1 and VD4 are located on the dorsal surfaces of the right pedal and visceral ganglia, respectively (Syed and Winlow, 1991). Mutual inhibitory synapses exist in vivo between RPeD1 and VD4 (Syed and Winlow, 1991). RPeD1 is dopaminergic (Cottrell et al., 1979) and does not synapse with another identified neuron, VD1 (Feng et al., 1996). When cultured in the presence of CM, RPeD1 and VD4 grow extensive neurites and reestablish appropriate inhibitory synapses (Syed et al., 1990), which are similar to those seen in vivo (Syed and Winlow, 1991). Typically, these neurite-neurite synapses between RPeD1 and VD4 in vitro (Syed et al., 1990) are distant from the somata and therefore are not amenable to direct electrophysiological analysis. In the present study, the somata of the neurons RPeD1 and VD4 were isolated in cell culture and immediately juxtaposed. We demonstrate that synapses similar to those observed in the intact brain reform reliably and selectively between the somata of RPeD1 and VD4 in the absence of neurite outgrowth. We also demonstrate that synapses between RPeD1 and VD4 require newly synthesized proteins to form but that synaptogenesis is independent of extrinsic growth factors or specific substrate requirement.

\section{MATERIALS AND METHODS}

Animals. Laboratory-raised stocks of the fresh water snail Lymnaea stagnalis were maintained at room temperature in well aerated pond water and fed lettuce. Snails with a shell length of 10-15 mm (approximate age 2-4 months) were used.

Cell culture. All animals were dissected under sterile conditions as described earlier (Syed et al., 1990). Specifically, animals were anesthetized with $10 \%$ Listerine solution in normal saline [(in $\mathrm{mm}$ ): $51.3 \mathrm{NaCl}$, 1.7 KCl, 4.0 $\mathrm{CaCl}_{2}$, and 1.5 $\mathrm{MgCl}_{2}$ ]-buffered HEPES to $\mathrm{pH}$ 7.9. The isolated central ring ganglia were washed several times (six to seven washes of $10 \mathrm{~min}$ each) with antibiotic saline (gentamycin, $50 \mu \mathrm{g} / \mathrm{ml}$ ). To prepare brain $\mathrm{CM}$, gentamycin $(20 \mu \mathrm{g} / \mathrm{ml})$-treated ganglia were incubated in defined medium (DM; L-15) contained in Sigma-Coate-treated glass petri dishes. These dishes were maintained in a humidified glass chamber for $3 \mathrm{~d}$ (for details, see Wong et al., 1981). Brains were subsequently removed, and the $\mathrm{CM}$ was frozen $\left(-20^{\circ} \mathrm{C}\right)$ until it was used. For cell culture, the antibiotic-treated ganglia were subsequently enzyme-treated and pinned down to the bottom of the dissection dish (Syed et al., 1990; Ridgway et al., 1991). Fire-polished glass pipettes were used to extract neurons, and the isolated cells were subsequently plated on plain plastic dishes (Falcon 3001), plain glass coverslips, or poly-Llysine-pretreated coverslips (Ridgway et al., 1991). Cells were plated in the presence of CM, DM, or saline. To obtain soma-soma pairs, the isolated somata of the identified neurons were isolated as described earlier (Syed et al., 1990) and juxtaposed immediately. The paired neurons were left undisturbed overnight. To test whether anisomycin $(12.5 \mu \mathrm{g} / \mathrm{ml})$ affected synaptogenesis, this drug was added to the culture dishes after $1-2 \mathrm{hr}$ of cell plating, and these dishes were then left undisturbed for 12-18 hr. To determine whether chronic anisomycin treatment affected synaptic transmission between soma-soma pairs, this protein synthesis inhibitor was added to the culture dishes $(12.5 \mu \mathrm{g} / \mathrm{ml})$ after $12-18 \mathrm{hr}$ of cell pairing. These anisomycin-treated cultures were left undisturbed for an additional $12-18 \mathrm{hr}$, and the synaptic transmission between the neurons was retested.

Electrophysiology. Simultaneous intracellular recordings were made using conventional sharp recording techniques as described previously (Syed and Winlow, 1991). Specifically, glass microelectrodes $(1.5 \mathrm{~mm}$ internal diameter; World Precision Instruments) were pulled on a vertical electrode puller (Kopf, 700C) and filled with a saturated solution of $\mathrm{K}_{2} \mathrm{SO}_{4}$ (resistance 20-40 M $\Omega$ ). Neurons were viewed under a Zeiss (Axiovert 135) inverted microscope (with Nomarski attachments) and impaled with Narishige (Tokyo, Japan) micromanipulators (MM 202 and MM 204). The intracellular signals were amplified via a preamplifier (NeuroData, IR-283), displayed on a storage oscilloscope (Fluka 2000, Buchs, Switzerland), and recorded on a Gould chart recorder (Gould TA 2405). Dopamine was applied exogenously via a pressure injection system (Eppendorf Microinjector, 5242). Glass electrodes (tip diameter 3-5 $\mu \mathrm{m}$ ) were filled with dopamine $\left(10^{-5} \mathrm{M}\right)$, which was then pressure-applied (2-5 psi pulses of 1-3 sec duration) directly to the neuronal somata. Neurons were judged to be electrically coupled if they permitted the passage of both depolarizing and hyperpolarizing current pulses in both directions.

All chemicals used in this study were obtained from Sigma, unless stated otherwise.

Electron microscopy. For electron microscopy, the electrophysiologically recorded somata were fixed for $2 \mathrm{hr}$ at room temperature in a mixture of $2 \%$ freshly prepared formaldehyde and $0.5 \%$ glutaraldehyde in $0.1 \mathrm{M}$ sodium cacodylate buffer, $\mathrm{pH} 7.4$, supplemented with $0.3 \mathrm{M}$ sucrose. After a $30 \mathrm{~min}$ post-fixation with $1 \% \mathrm{OsO}_{4}$, the cells were dehydrated in an ascending series of alcohol and embedded in Epon. The area of interest on the plastic culture dish was cut out, glued to a small block of Epon, and sectioned. After post-staining with lead and uranyl acetate, the sectioned material was examined under a JOELP 1010 electron microscope. 


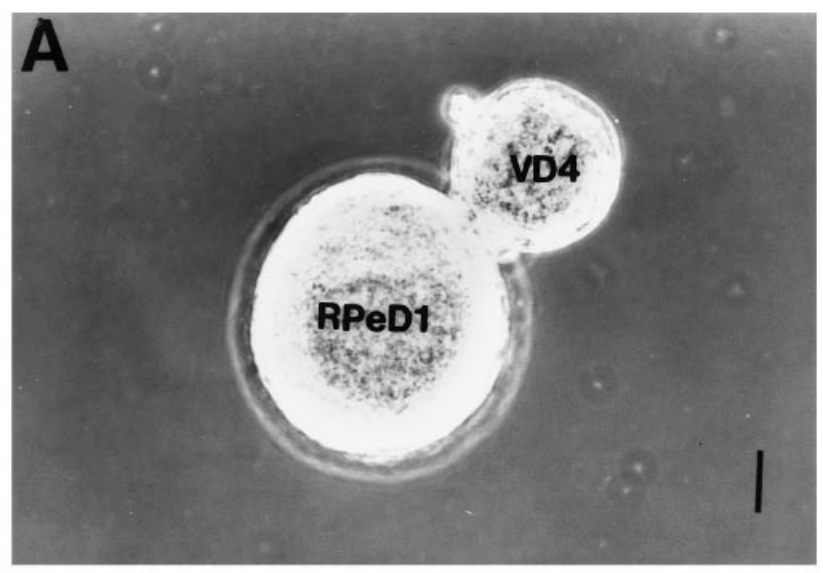

B

RPeD1
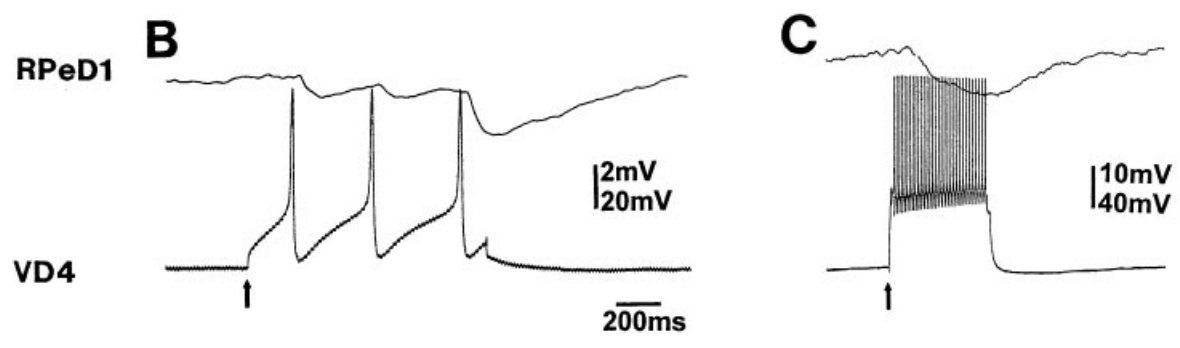

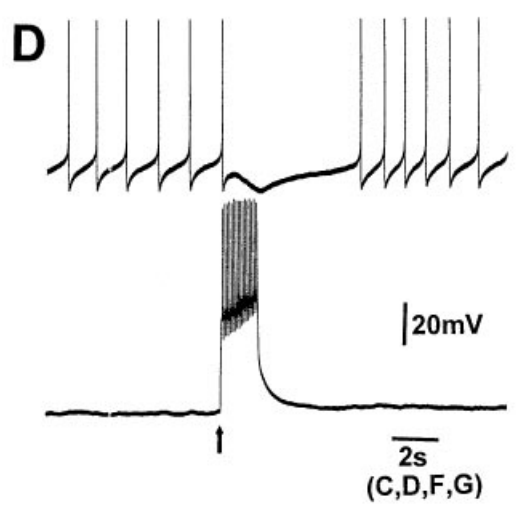

$(C, D, F, G)$

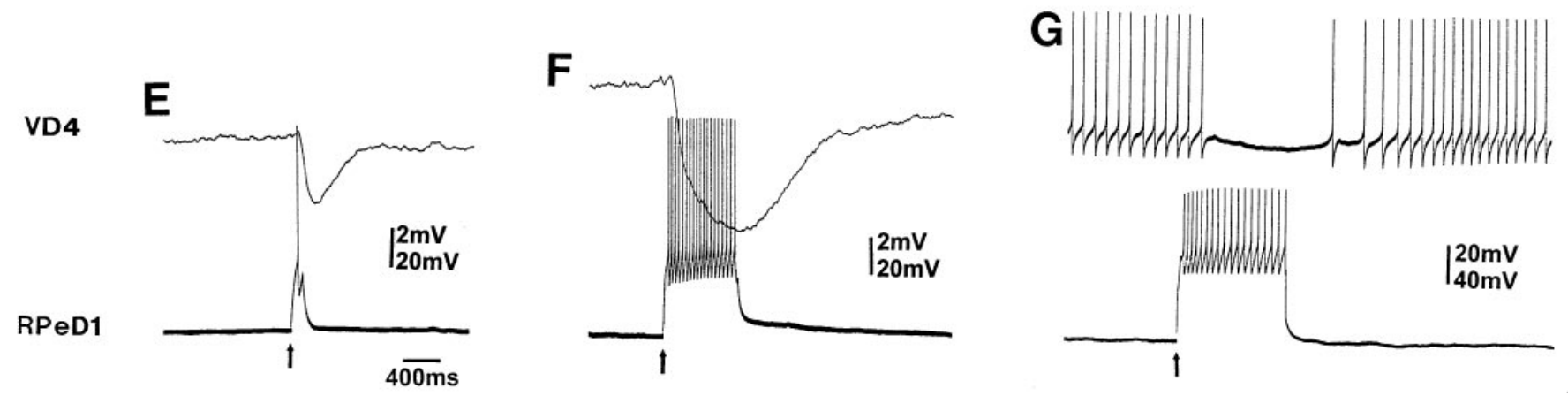

Figure 2. Specific inhibitory synapses between the somata of neurons RPeD1 and VD4 reestablish in cell culture. RPeD1 and VD4 were paired in a soma-soma configuration $(A)$, and simultaneous intracellular recordings were made. After 12-24 hr of plating, mutual inhibitory synapses reformed between these cells. Specifically, either single $(B)$ or compound action potentials in VD4 $(C, D$, arrows) produced unitary $(B)$ or compound postsynaptic potentials in $\mathrm{RPeD} 1(C, D)$, respectively, and vice versa $(E-G)$. Note: these synapses were consistent with those seen in the intact brain.

\section{RESULTS}

Neuron RPeD1 is located in the right pedal ganglion, and VD1 and VD4 are situated in the visceral ganglion (Fig. 1A). Mutual inhibitory synapses exist in vivo between RPeD1 and VD4 (Fig. $1 B$ ), whereas no synaptic connections are found between RPeD1 and VD1 (Fig. 1B). In the first series of experiments, we demonstrate that specific synapses between RPeD1 and VD4 reform in a soma-soma configuration. A similar cell pairing between RPeD1 and VD1 did not result in synaptogenesis between these cells.

\section{Specific inhibitory synapses between the cell somata of neurons RPeD1 and VD4 reformed in cell culture}

Somata of RPeD1 and VD4 were isolated individually as described previously (Syed et al., 1990, Ridgway et al., 1991) and maintained on the poly-L-lysine-coated dishes containing CM (Fig. 2A). After 12-24 hr in vitro, simultaneous intracellular recordings were made from both neurons. Mutual inhibitory synapses similar to those seen in vivo regularly reformed between the cell somata $(86 \% ; n=50)$. For example, single (Fig. $2 B$ ) or compound action potentials in VD4 (Fig. 2C,D) produced unitary (Fig. $2 B$ ) or compound postsynaptic potentials in RPeD1 (Fig. $2 C, D)$, respectively, and vice versa (Fig. $2 E-G$ ). It is important to note that the nature of these synapses between RPeD1 and VD4 is variable in the intact brain, and they are often observed as either unitary or compound IPSPs (Syed et al., 1990; Syed and Winlow, 1991) (Fig. 2). These data are summarized in Figure 3, which shows that of 50 cell pairs investigated in this study, 43 formed reciprocal, inhibitory chemical synapses and three exhibited electrical synapses, whereas neither chemical nor electrical synapses were observed between the remaining four cell pairs. This study is the first to reconstruct synapses between the somata of identified Lymnaea neurons.

\section{RPeD1 did not synapse with an identified nontarget neuron VD1}

To test the specificity of target cell selection, RPeD1 was paired with neuron VD1. Although in vivo the neuron VD1 is located in 

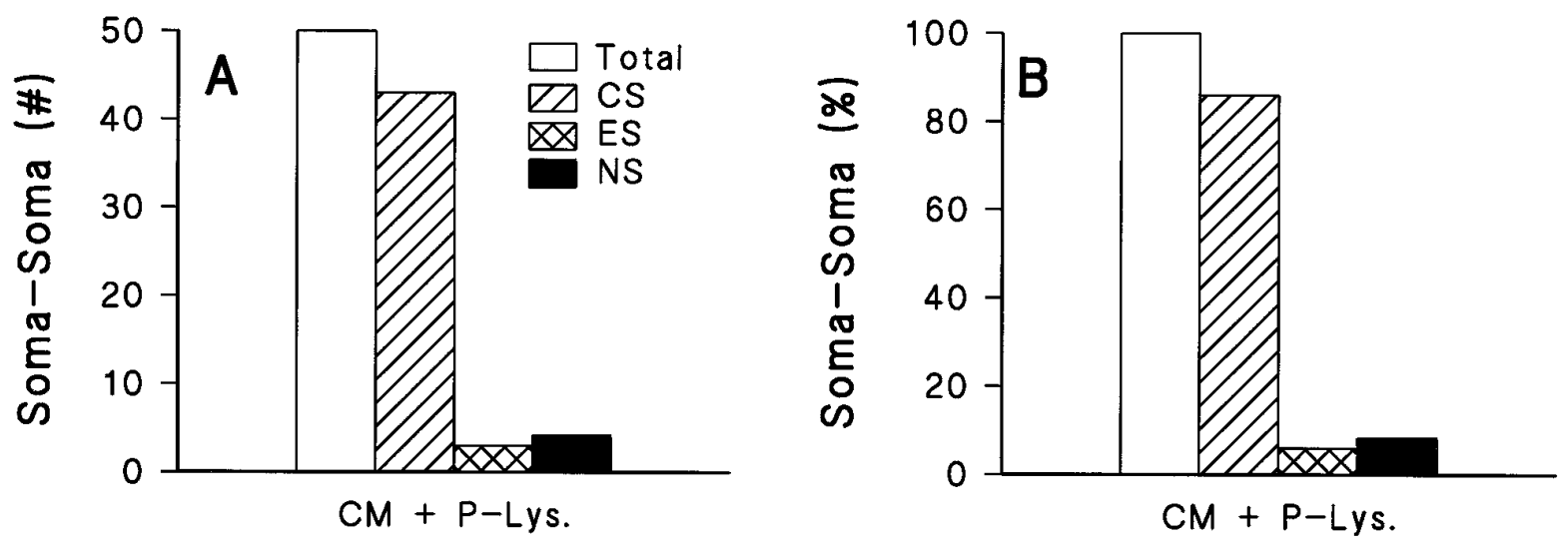

Figure 3. Chemical synapses between RPeD1 and VD4 formed reliably and consistently in a soma-soma configuration. When plated on poly-L-lysinecoated dishes containing CM, both RPeD1 and VD4 formed specific inhibitory connections with each other. $A$ shows total numbers of soma-soma pairs that were tested in this study, whereas $B$ shows percentage of cells that were found to be synaptically connected. Total, The total number of cells plated; $C S$, chemical synapses; $E S$, electrical synapses; $N S$, no synapses detected.

the same ganglion as VD4 and is in close proximity to the neurites of RPeD1 (Haydon et al., 1985), it does not receive synaptic input from RPeD1 (Feng et., 1996). An additional reason for selecting this particular nontarget cell was its ability to exhibit an electrophysiological response to exogenously applied dopamine, the neurotransmitter of RPeD1 (Magoski et al., 1995). $\mathrm{RPeD} 1$ was isolated in vitro and paired with VD1 (Fig. $4 A$ ) as described above. Simultaneous intracellular recordings after 12-24 hr of pairing did not reveal an electrophysiologically detectable synapse between the cells $(n=18)$ (Fig. $4 B, C)$. To demonstrate that VD1 expresses functional dopamine receptors, dopamine was applied exogenously. Pressure application of dopamine $\left(10^{-5} \mathrm{M} ; 0.5-1.0 \mathrm{sec}\right.$ pulses of $\left.1-2 \mathrm{psi}\right)$ either induced a hyperpolarizing response at rest $(n=5)$ (Fig. $4 D)$ or terminated spiking activity of a spontaneously active VD1 $(n=5)$ (Fig. $4 E)$. These data demonstrated that RPeD1 did not form a soma-soma synapse with a dopamine-responsive nontarget cell.

Together, these data show that in cell culture RPeD1 reestablished specific synapses with VD4 but not VD1. They do not rule out, however, the possibility that the electrophysiologically recorded synaptic responses of RPeD1 and VD4 may be attributable to diff use, nonsynaptic transmitter release.

\section{Inhibitory responses recorded from soma-soma paired RPeD1 and VD4 are synaptic and target cell specific}

To rule out nonsynaptic transmitter release by soma-soma paired RPeD1 and VD4, and to demonstrate that a VD1-contacted RPeD1 was indeed capable of transmitter secretion (synaptic), three cells (RPeD1, VD4, and VD1) were paired in a configuration such that RPeD1 contacted the cell somata of both VD1 and VD4 (Fig. 5A). Because both VD4 and VD1 are dopamine responsive, we anticipated that nonsynaptic dopamine release from RPeD1 should be detectable by both of these neurons. Under these experimental conditions, however, we found that VD4 but not VD1 exhibited an inhibitory response to the electrical stimulation of RPeD1 $(n=4)$ (Fig. $5 B, C)$. Note that VD1 did exhibit an inhibitory response to exogenously applied dopamine $\left(n=4 ; 10^{-5} \mathrm{M}\right)$ (Fig. $\left.5 D\right)$, showing that it did express functional dopamine receptors.

Taken together, these data demonstrate that (1) RPeD1 in vitro is selective in its target cell, (2) transmitter release by RPeD1 was synaptic, and (3) the presence of dopamine receptors is insufficient to induce VD1 synaptogenesis with RPeD1.

\section{Morphological evidence for chemical synapses between the soma-soma paired neurons RPeD1 and VD4}

We next sought morphological evidence for soma-soma synapses between the paired neurons. RPeD1 and VD4 were paired as described above, and intracellular recordings were made to confirm synaptic interactions between the neurons. Electrophysiologically tested neurons were then fixed, sectioned, and analyzed by electron microscopy. Figure 6 shows electron micrographs of soma-soma contacts between VD4 and a RPeD1. RPeD1 extended "finger-like" projections that invaginated into the plasma membrane of VD4 $(n=4)$. These invaginations contained clusters of typical dopamine-containing vesicles in RPeD1 (Fig. 6) (also see Spencer et al., 1997). Because VD4 is a peptidergic neuron, its vesicles are morphologically distinct from those of RPeD1 (dopaminergic). It is also important to note that these molluscan "synapse-like" structures are characteristic of Lymnaea synapses seen in vivo (Roubos and Moorer-van Delft, 1979). These data therefore are consistent with previously published studies and provide morphological evidence for molluscan "synapse-like" structures between soma-soma paired neurons RPeD1 and VD4.

\section{Synaptogenesis between RPeD1 and VD4 somata required de novo protein synthesis}

To test whether newly synthesized proteins were required for synapse formation between paired somata of RPeD1 and VD4, these cells were cultured as described above but in the presence of anisomysin (a nonspecific protein synthesis inhibitor; 12.5 $\mu \mathrm{g} / \mathrm{ml}$ ). Simultaneous intracellular recordings were made after 18-24 hr of soma-soma pairing. Anisomysin completely blocked the development of synaptic responses between RPeD1 and VD4 $(n=24)$ (Fig. 7), despite the fact that both neurons exhibited normal resting membrane potential and action potential amplitude and duration (data not shown). Moreover, these soma-soma paired neurons continued to exhibit normal (hyperpolarizing) electrophysiological responses to exogenously applied dopamine $(n=7)$ (Fig. 8), suggesting that the anisomysin treatment did not affect the postsynaptic dopamine response in VD4.

To rule out the possibility that prolonged anisomycin treatment had nonspecific toxic effects, already synapsed RPeD1-VD4 were cultured and then subjected to chronic anisomycin treatment 


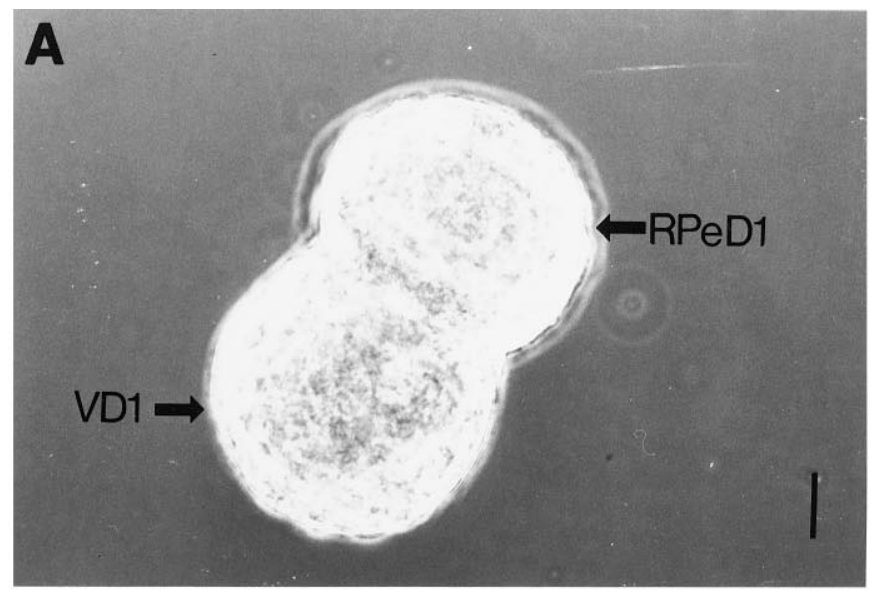

B

VD1

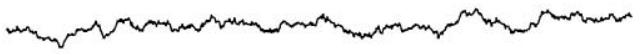

C
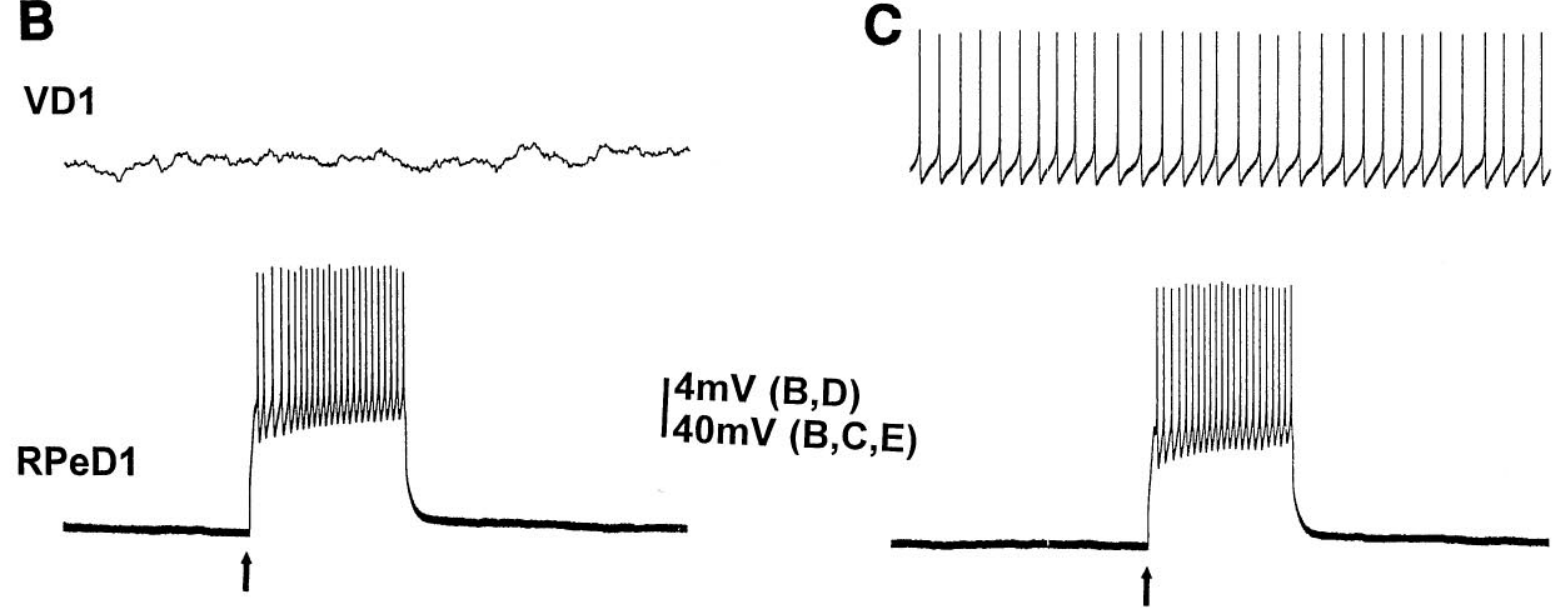

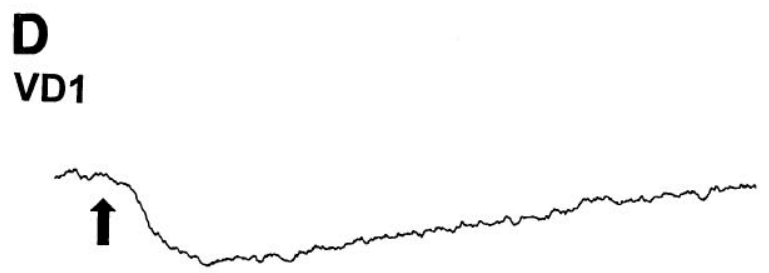

Dopamine $\left(10^{-5} \mathrm{M}\right)$
E

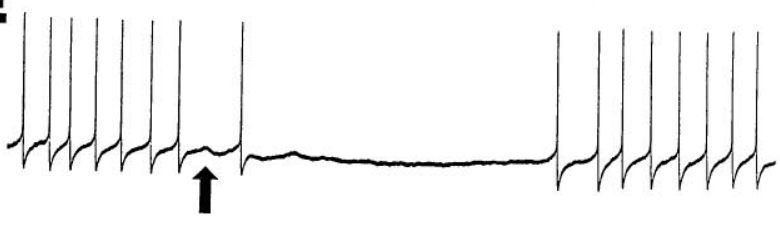

Dopamine $\left(10^{-5} \mathrm{M}\right)$

Figure 4. RPeD1 did not synapse with its nontarget neuron VD1. When RPeD1 was soma-soma paired with its in vivo nonsynaptic partner cell VD1 ( $A$ ) and RPeD1 was stimulated intracellularly (arrow), an electrophysiologically detectable synapse was not found ( $B, C)$. Note that VD1 did indeed exhibit an electrophysiological response to exogenously applied dopamine $(D, E$, arrows). Both neurons were paired on poly-L-lysine-coated dishes containing CM.

(6-24 hr). Anisomycin did not affect synaptic transmission between RPeD1 and VD4 $(n=5)$ (Fig. 9).

Taken together, these data demonstrate that soma-soma synapses between RPeD1 and VD4 require new protein synthesis. To test whether synaptogenesis was contingent on extrinsic growth factors present in the CM, and/or any given substrate molecule (such as poly-L-lysine), we attempted to reconstruct RPeD1-VD4 synapses in the absence of these factors.

\section{Synaptogenesis between soma-soma paired RPeD1 and VD4 was independent of extrinsic trophic factors and substrate adhesion molecules}

Neurite outgrowth by adult Lymnaea neurons is dependent on trophic factors present in CM (Syed et al., 1990; Ridgway et al.,
1991). To determine whether these Lymnaea CM-derived factors are also necessary for synapse formation, RPeD1 and VD4 were juxtaposed as described above but in the absence of CM (i.e., in either DM, $n=22$, or saline, $n=7)$. Under these experimental conditions, synapses reformed between RPeD1 and VD4 $(n=$ 22) (Fig. 10). Both quantitatively and qualitatively (IPSP duration and amplitude; data not shown), these synapses were similar to those observed in the presence of CM (Fig. 3).

In previously published studies, poly-L-lysine was a prerequisite for neurite outgrowth (Wong et al., 1981; Syed et al., 1990; Ridgway et al., 1991). To test its importance for synapse formation, RPeD1 and VD4 soma-soma pairs were plated on either plain glass coverslips $(n=10)$ or plain plastic culture dishes $(n=$ 

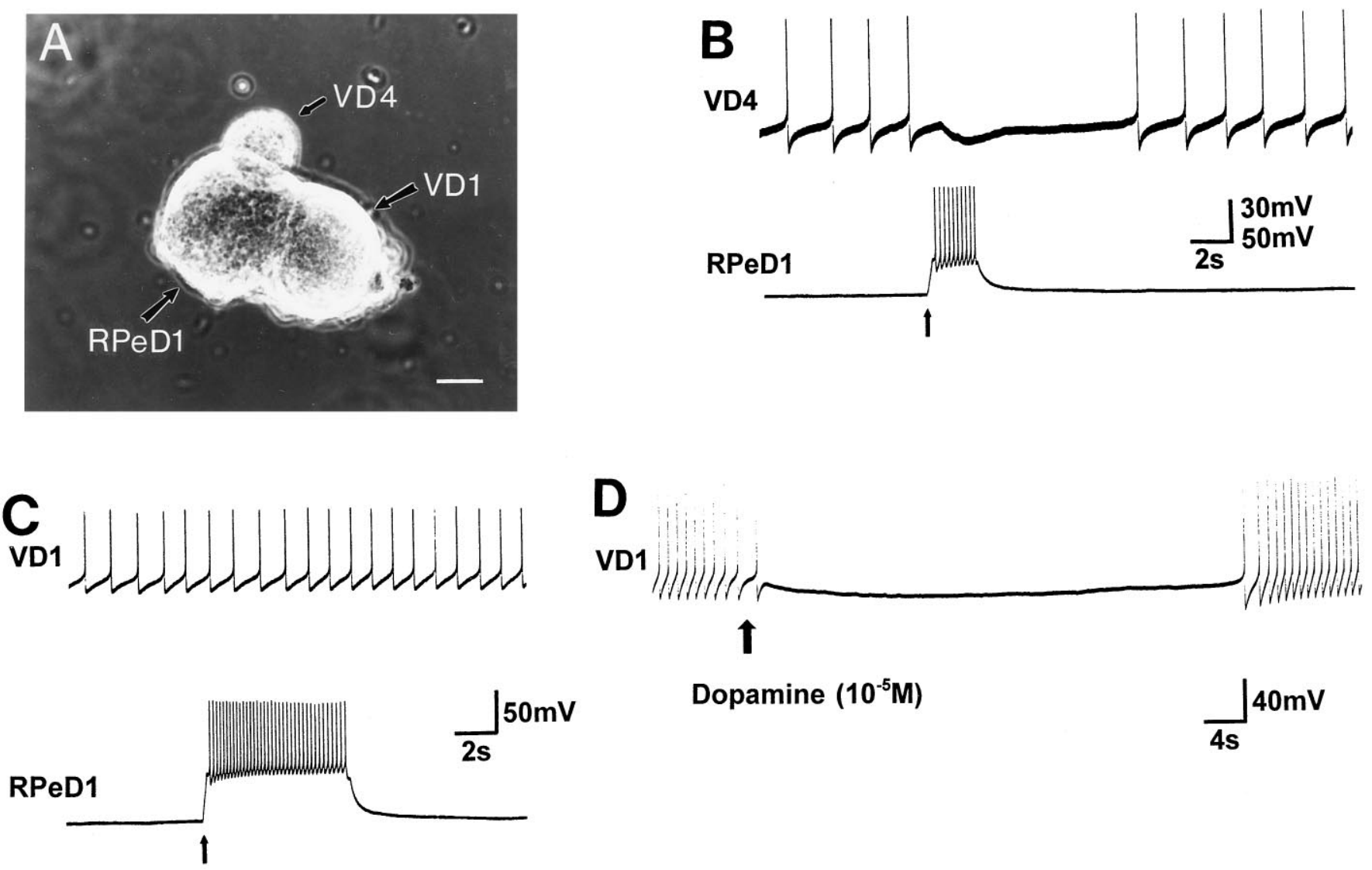

Dopamine $\left(10^{-5} \mathrm{M}\right)$

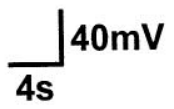

Figure 5. The inhibitory response recorded from a soma-soma paired RPeD1 and VD4 was synaptic and target cell specific. To rule out the possibility of nonsynaptic transmitter release by soma-soma paired neurons, RPeD1, VD4, and VD1 were paired together $(A)$. Because both VD4 and VD1 are dopamine responsive, we anticipated that a diffuse release of dopamine should be detectable by both of these neurons. Under these experimental conditions, we found VD4 $(B)$ but not VD1 $(C)$ to exhibit an inhibitory response to RPeD1 stimulation (arrows). Note that VD1, however, did exhibit an inhibitory response to exogenously applied dopamine (D, arrow).

10) (Falcon 3001). Soma-soma synapses between RPeD1 and VD4 formed in the absence of substrate coating (DM + glass, $n=10 ; \mathrm{DM}+$ plastic, $n=10$ ) (Fig. 11), suggesting that poly-Llysine is not required for synapse formation between the somata pairs.

Taken together, these data are consistent with the hypotheses that (1) specific inhibitory synapses between RPeD1 and VD4 form in a soma-soma configuration and (2) this synaptogenesis follows an inherent program that is contingent on new protein synthesis but does not require extrinsic growth factors or substrate adhesion molecules.

\section{DISCUSSION}

Because of its anatomical complexity, little is known regarding the intrinsic and extrinsic factors that are necessary for synapse formation in the nervous system. Synapse formation between individually defined pre- and postsynaptic neurons cannot be studied in vivo at the present time, especially under an extracellularly controlled environment. Various researchers interested in synapse formation have resorted, therefore, to simple cell culture techniques in which individually definable neurons can be extracted from the nervous system and studied in isolation under controlled experimental conditions (Dagan and Levitan, 1981; Bulloch and Syed, 1992; Haydon and Drapeau, 1995). Notwithstanding the fact that these cell culture conditions are artificial and may not reflect those that occur naturally, these studies have provided insights into cellular mechanisms that are fundamental to synapse formation (Chow and Poo, 1985; Bulloch and Syed, 1992; Hawver and Schacher, 1993; Catarsi et al., 1995; Drapeau et al., 1995; Haydon and Drapeau, 1995; Mennerick et al., 1995).

To gain direct and simultaneous access to both pre- and postsynaptic somata and their synaptic machinery, Haydon (1988) developed synapses between the somata of identified Helisoma neurons in the absence of neurite outgrowth. Specifically, the isolated somata of neurons B5 and B19 juxtaposed in culture developed inhibitory soma-soma synapses. Although these synapses do not exist in vivo, this model nevertheless provided insights into the secretory assembly that mediated synaptic transmission between these neurons (Man-Son-Hing et al., 1989; Zoran et al., 1993; Zoran and Poyer, 1996). Recently, Klein (1994) used this approach to reconstructed specific synapses between the Aplysia sensory and motor neurons that are appropriate and similar to those seen in vivo. In the present study, we reconstructed the mutually inhibitory and specific synapse between the somata of identified Lymnaea respiratory neurons. These synapses were similar to those found in vivo (Syed and Winlow, 1991) and also resembled those that were reconstructed between the neurites of these neurons in vitro (Syed et al., 1990). Our approach for obtaining soma-soma synapses was conceptually similar to that of Haydon (1988) and Klein (1994), but there were several experimental differences. For instance, both Haydon (1988) and 


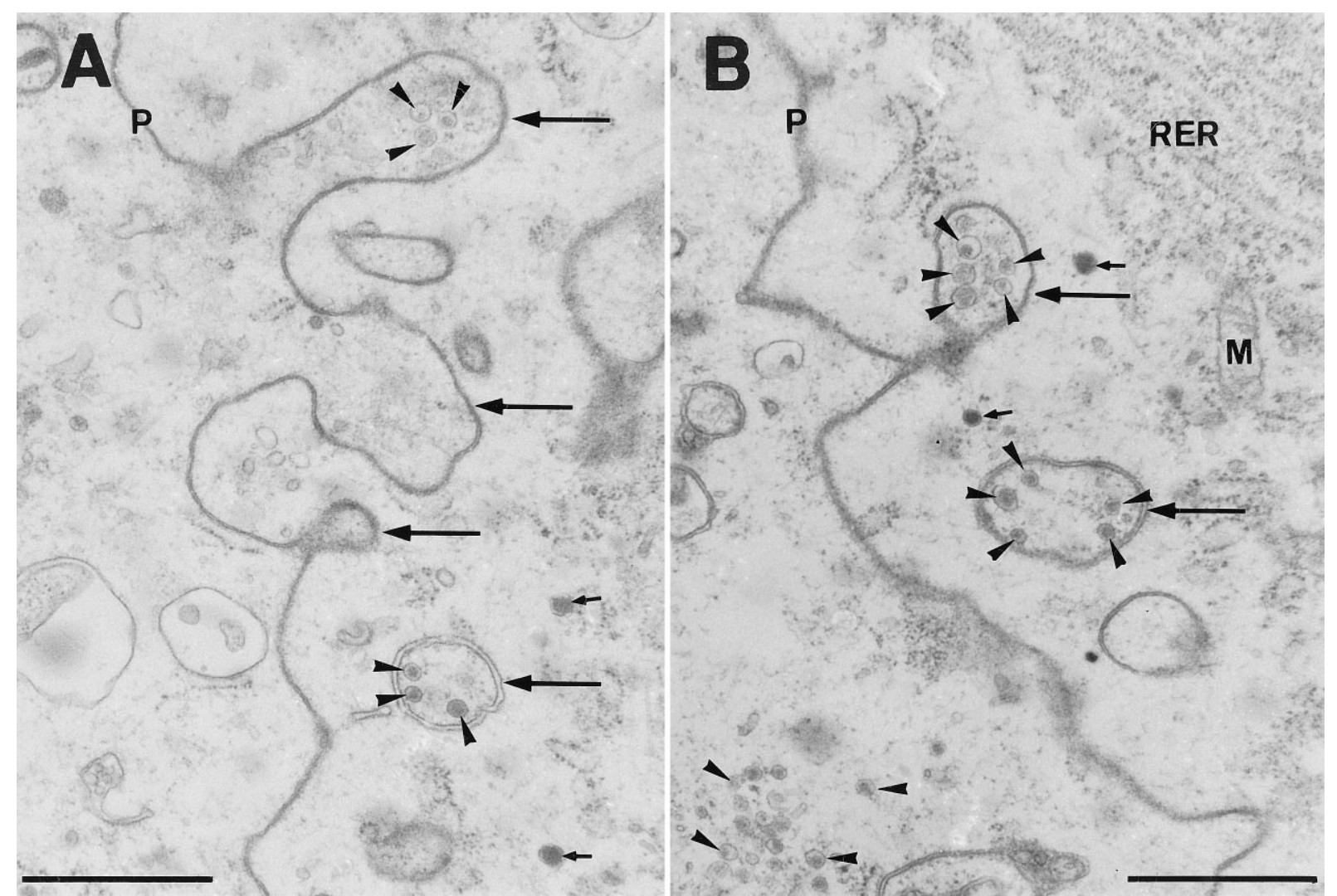

Figure 6. Morphological evidence for chemical synapses between the soma-soma paired neurons RPeD1 and VD4. Electron micrographs showing soma-soma contacts between two different pairs $(A, B)$ of VD4 (right) and RPeD1 (left) neurons. RPeD1 extended "finger-like" projections that invaginated into the plasma membrane $(P)$ of VD4 (arrows). Within these invaginations were contained clusters of typical dopamine-containing vesicles (small arrowheads). Note that dense-cored secretory vesicles of VD4 (small arrows) were morphologically distinct from those of RPeD1. It is also important to note that these "molluscan synapse-like" structures were characteristic of Lymnaea synapses seen in vivo (Roubos and Moorer-van Delft, 1979). P, Plasma membrane; RER, rough endoplasmic reticulum; $M$, mitochondrion. Scale bar, $100 \mathrm{~nm}$.

Klein (1994) needed to maintain their pre- and postsynaptic neurons in isolation from each other for $24-48 \mathrm{hr}$ before cell pairing. The paired neurons were then juxtaposed under experimental conditions that prevented neuronal adhesion to the polyL-lysine substrate for an additional $24 \mathrm{hr}$. These neurons were then plated on poly-L-lysine dishes containing either CM (Helisoma) or hemolymph (Aplysia) and recorded electrophysiologically. Our approach resembled that adopted previously for leech neurons (Nicholls et al., 1990), in which the cells were paired immediately after isolation. The time course of synaptogenesis between these two species was similar (4-12 hr), but the incidence of chemical synapses between soma-soma pairs was much higher in Lymnaea (88\%) than in leech (30\%) (Nicholls et al., 1990). We found that soma-soma synapses between Lymnaea neurons (RPeD1 and VD4) were almost always nonfatiguing; i.e., synaptic transmission continued unabated, despite repeated stimulation of the presynaptic cells. Because synapses between RPeD1 and VD4 formed reliably (88\%) within 4 (data not shown) to $18 \mathrm{hr}$ (Fig. 3), we believe that our approach is simpler than that used elsewhere and will enable us to study cellular and molecular changes during the early stages of synaptogenesis. This study is not only the first to demonstrate soma-soma synapses between Lymnaea neurons, but it also provides first evidence that specific, reciprocal inhibitory synapses between the somata of identified neurons can be reconstructed in cell culture.

It can be argued that in a soma-soma configuration, neurons are "forced" to form synapses that may not be natural. Because soma-soma synapses between RPeD1 and VD4 were similar to those seen in vivo, we are confident that these synapses are appropriate and normal. Moreover, if these neurons were "forced" into forming synapses, then RPeD1 also might have been expected to form a synapse with its nontarget cell VD1 (Figs. 4, 5); however, this was not the case. These data are consistent with other studies in which the specificity of synaptogenesis between identified neurons was also shown to be preserved in the soma-soma configuration (Nicholls et al., 1990; Klein, 1994). The data presented in Figure 5 deal with an additional issue, i.e., whether the electrophysiological responses recorded from RPeD1 and VD4 were indeed "synaptic" and not caused by a nonsynaptic (diffused) release of neurotransmitter. Had transmitter release from RPeD1 been nonsynaptic and diffuse, then any dopamine-responsive neuron, such as VD1, should exhibit an electrophysiological response after RPeD1 stimulation. This was not the case. Despite the fact that the membrane contact of VD1 with RPeD1 was more extensive (larger somata) than VD4, and that VD1 responded to exogenous dopamine, we detected synaptic release only between RPeD1 and VD4. This study, therefore, is the first to examine the issue of synaptic versus nonsynaptic (diffuse) release of transmitter from the synapsed neurons in any preparation studied to date.

Taken together, these data show that (1) RPeD1 is specific in its target cell selection, (2) transmitter release between the neurons RPeD1 and VD4 is most likely synaptic, and (3) the presence of electrophysiologically functional dopamine receptors on 

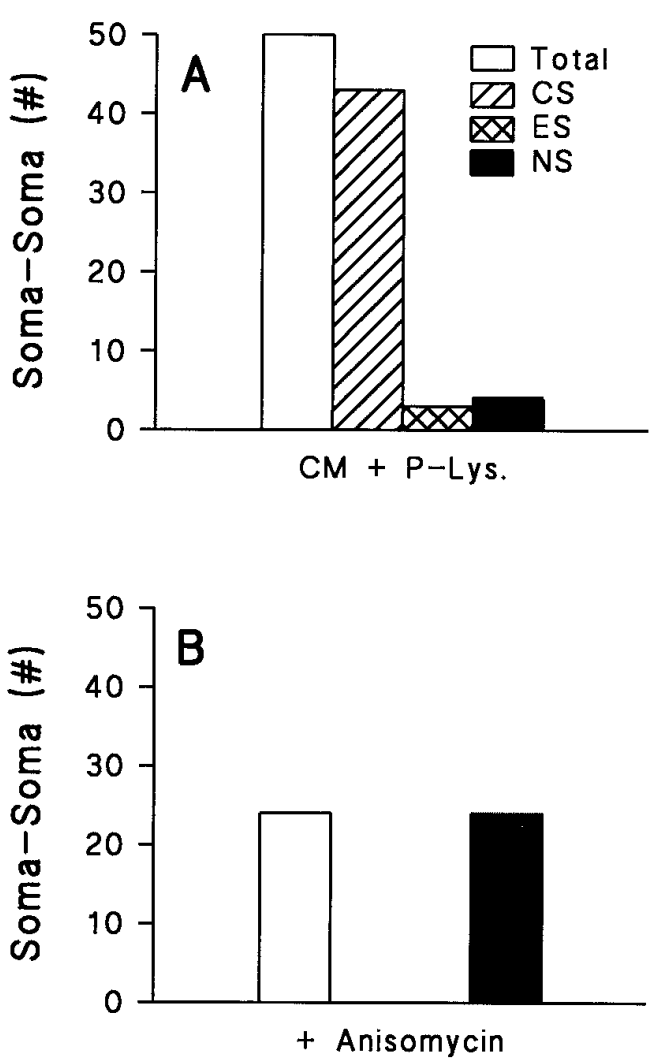

Figure 7. Protein synthesis was required for synapse formation between soma-soma-paired neurons RPeD1 and VD4. RPeD1 and VD4 were cultured on poly-L-lysine substrate in the presence of CM. Anisomycin $(12.5 \mu \mathrm{g} / \mathrm{ml})$ was added to the culture dishes after $1-2 \mathrm{hr}$ of cell pairing. As compared with the control preparations (no anisomycin) $(A)$, anisomycin $(B)$ completely blocked the formation of electrophysiologically detectable synapses (recorded after $18-24 \mathrm{hr}$ of post-plating) $(n=24)$. $C S$, Chemical synapses; $E S$, electrical synapses; $N S$, no synapses.

VD1 is not sufficient for its synaptogenesis with RPeD1. In other words, if transmitter-receptor interactions were sufficient to generate specificity of synaptic contacts in the nervous system, then RPeD1 also would have synapsed with VD1.

Because "synapse" is a morphological term, we sought morphological profiles of synapses between soma-soma contacted neurons. Figure 6 shows such a molluscan synapse-like structure, with clustered transmitter vesicles within the finger-like projections that invaginated into the plasma membrane of the postsynaptic cell. These synaptic structures have been described previously for most vertebrate synapses, albeit they are not so unusual for molluscan species such as Lymnaea (Roubos et al., 1979), Aplysia (Klein, 1994), and Helisoma (R. Berdan, personal communication). Despite an extensive search, we were unable to find profiles of classic synapses such as those observed in most vertebrate species.

De novo protein synthesis is considered important for synapse plasticity, modulation, learning, and memory (Steward and Falk, 1986; Schacher et al., 1988; Steward et al., 1988), but its involvement in synapse formation has not been fully explored. In the present study, anisomycin, a nonspecific protein synthesis inhibitor, blocked synapse formation between RPeD1 and VD4 but did not perturb neuronal excitability and nor did its chronic application alter preexisting synaptic transmission between the neurons. Taken together, our data are consistent with the hypoth-

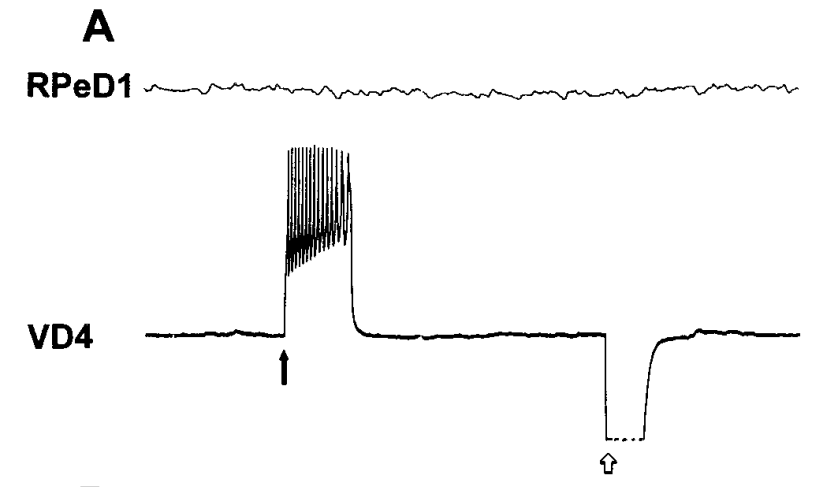

B
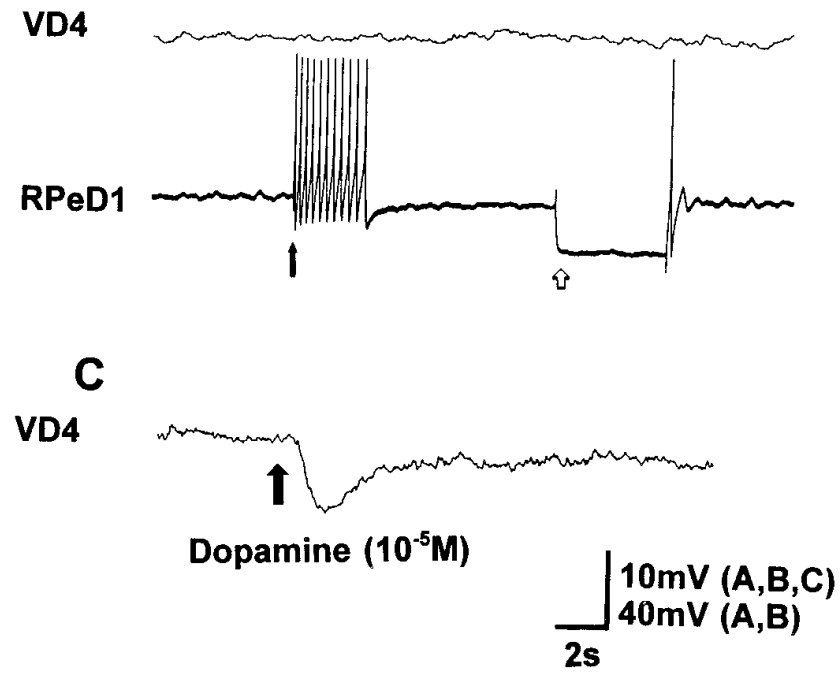

Figure 8. Anisomycin blocked synapse formation between RPeD1 and VD4 but did not affect the postsynaptic dopamine response in VD4. Synapses between RPeD1 and VD4 failed to form in the presence of anisomysin $(A, B)$. Intracellular injections of either depolarizing (solid arrows) or hyperpolarizing current injections (to rule out the presence of electrical synapses) (open arrows) did not produce an electrophysiological response in either RPeD1 $(A)$ or VD4 $(B)$. $C$, Exogenous application of dopamine (arrow), however, induced a hyperpolarizing response in VD4.

esis that soma-soma synapse formation between RPeD1 and $\mathrm{VD} 4$ requires de novo protein synthesis. Whether de novo protein synthesis is contingent on cell-cell contacts between RPeD1 and VD4 or occurs independently was not tested in the present study.

We have shown previously that neurite outgrowth by adult Lymnaea neurons is regulated by various growth factors present in the CM (Syed et al., 1990; Fainzilber et al., 1996). Moreover, murine nerve growth factor (NGF) (Ridgway et al., 1991) and ciliary neurotrophic factor (CNTF) (Syed et al., 1996) can also initiate neurite outgrowth by Lymnaea neurons, but synaptogenesis between select pre- and postsynaptic neurons in this species is differentially regulated. For instance, neurons cultured in the presence of NGF exhibited both neurite outgrowth and synaptogenesis, whereas in the presence of CNTF these neurons sprouted extensively but failed to establish electrophysiologically detectable synapses (Syed et al., 1996). Because in the present study we demonstrated that extrinsic trophic factors are not required for synapse formation between RPeD1 and VD4, we believe that in our previous studies CNTF may have exerted synapse suppressive affects on these neurons. This possibility remains to be investigated. The data presented in this study do 

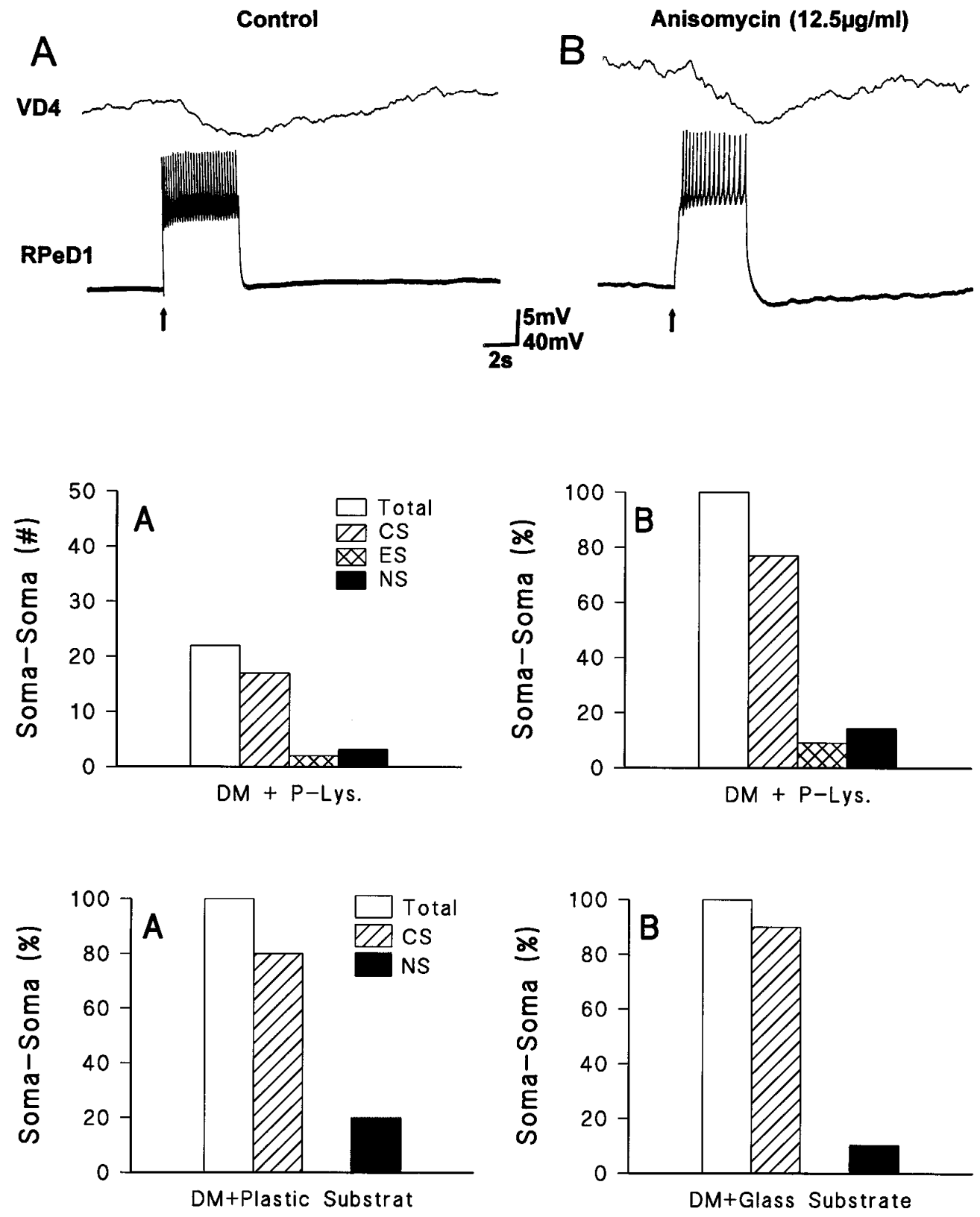
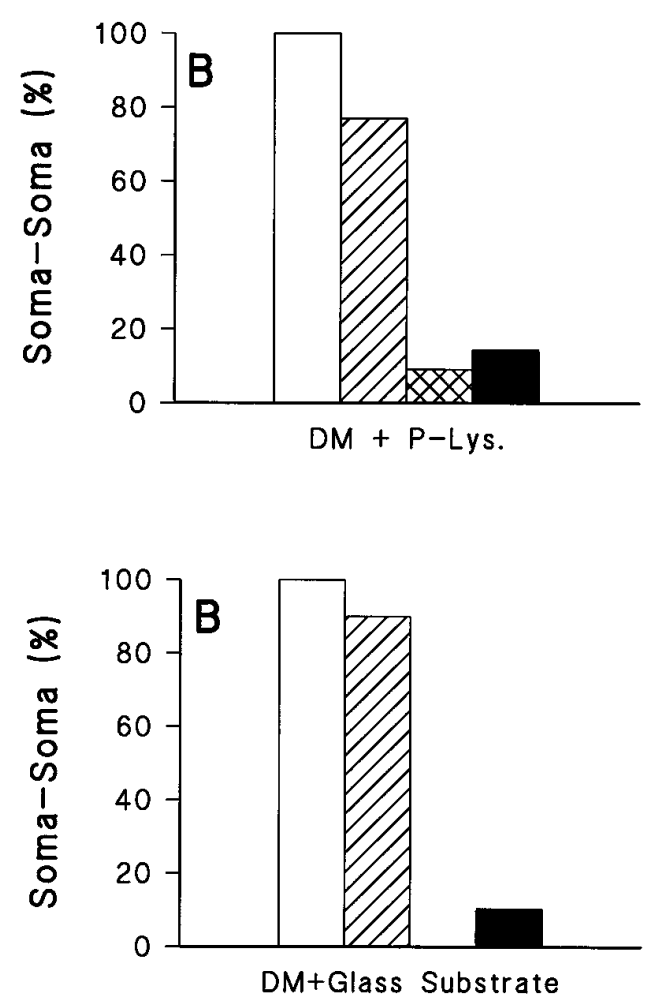

Figure 9. Anisomycin did not affect synaptic transmission between RPeD1 and VD4. To test for the possible toxic effects of anisomysin on cultured neurons, synapsed RPeD1 and VD4 pairs were subjected to chronic anisomysin treatment $(6-24 \mathrm{hr})$. These prolonged incubations with anisomycin did not affect synaptic transmission between RPeD1 and VD4.

Figure 10. Synaptogenesis between soma-soma paired RPeD1 and VD4 was independent of extrinsic trophic factors. RPeD1 and VD4 were juxtaposed in the presence of DM on polyL-lysine-coated dishes. Synapses between RPeD1 and VD4 reformed reliably in the absence of conditioning factors. $A$ shows total number of synapses tested in the presence of DM, whereas $B$ shows percentage of neurons that were either synaptically connected or not connected. The incidence of synapses between the cell pairs (in the absence of CM) was similar to that seen in the presence of CM (Fig. 3).

Figure 11. Substrate-independent synaptogenesis between soma-soma paired neurons RPeD1 and VD4. To test whether poly-L-lysine substrate was necessary for synapse formation between RPeD1 and VD4, these cells were paired either on plain glass coverslips $(A)$ or plastic culture dishes (Falcon 3001) (B). The incidence of synapses between soma-soma paired cells is represented in terms of percentage. Synapses between RPeD1 and VD4 formed regardless of the substrate used. not rule out the possibility that various, as yet unidentified, trophic factors released by RPeD1 or VD4 or both may be involved in synaptogenesis. This assumption is consistent with other studies in which specific trophic factors secreted by either the postsynaptic target or the presynaptic neuron have been shown to modulate the secretory machinery of the synaptic partner cells (Berninger and Poo, 1996; Stoop and Poo, 1996).

Various cell and substrate adhesion molecules have been implicated in target cell selection and specific synapse formation (Chow, 1990; Zhu et al., 1994; Noakes et al., 1995). Although their involvement in axonal pathfinding and target cell selection is established, their precise role in synaptogenesis remains to be determined (Doherty and Walsh, 1992). For instance, cell adhesion molecules play roles in neurite outgrowth, synapse formation, and plasticity in various animal preparations (Douglas and Itoh, 1996), whereas in other preparations they are not considered necessary for synaptogenesis (Mehrke et al., 1984). Because neurite outgrowth by Lymnaea neurons is highly dependent on a
poly-L-lysine substrate (Syed et al., 1990), the present study tested whether substrate molecules are also necessary for synapse formation. Because synapses between RPeD1 and VD4 somata formed in the absence of any substrate, our data show that they are not obligatory for synaptogenesis.

In conclusion, this study provided the first direct evidence that de novo protein synthesis was required for synapse formation and demonstrated that extrinsic growth factors and substrate molecules were not needed. Because neurons used in the present study are important components of the central respiratory rhythm generator, the soma-soma synapse model will now allow us to explore the cellular, biophysical, and synaptic mechanisms that govern respiratory rhythmogenesis in Lymnaea. Moreover, because both synapses and somata are amenable to direct molecular and electrophysiological analysis, this model provides us with an unparalleled opportunity to identify various gene products (van Kesteren et al., 1996) and ion channels that are regulated during synaptogenesis. 


\section{REFERENCES}

Ambron RT, Den H, Schacher S (1985) Synaptogenesis by single identified neurons in vitro: contribution of rapidly transported and newly synthesized proteins. J Neurosci 5:2857-2865.

Berninger B, Poo M-M (1996) Fast actions of neurotrophic factors. Curr Opin Neurobiol 6:324-330.

Bonhoeffer T (1996) Neurotrophins and activity dependent development of the neocortex. Curr Opin Neurobiol 6:119-129.

Braun S, Croizat B, Lagrange MC, Warter JM, Poindron P (1996) Neurotrophins increase motoneuron's ability to innervate skeletal muscle fibers in rat spinal cord-human muscle cocultures. J Neurol Sci 136:695-699.

Bulloch AGM, Syed NI (1992) Reconstruction of neuronal networks in culture. Trend Neurosci 15:422-427.

Catarsi S, Ching S, Merz DC, Drapeau P (1995) Tyrosine phosphorylation during synapse formation between identified leech neurons. J Physiol (Lond) 485:775-786.

Cellerino A, Maffei L (1996) The action of neurotrophins in the development and plasticity of the visual cortex. Prog Neurobiol 49:53-71.

Chiquet M, Nicholls JG (1987) Neurite outgrowth and synapse formation by identified leech neurons in culture. J Exp Biol 32:191-206.

Chow I (1990) Cell-cell interactions during synaptogenesis. J Physiol (Paris) 84:121-127.

Chow I, Poo MM (1985) Release of acetylcholine from embryonic neurons upon contact with muscle cell. J Neurosci 5:1076-1082.

Cottrell GA, Abernathy KB, Barrand MA (1979) Large aminecontaining neurons in the central ganglia of Lymnaea stagnalis. Cell Tissue Res 198:217-235.

Dagan D, Levitan IB (1981) Isolated identified Aplysia neurons in cell culture. J Neurosci 1:736-740.

Doherty P, Walsh FS (1989) Neurite guidance molecules. Curr Opin Cell Biol 1:1102-1106.

Doherty P, Walsh FS (1992) Cell adhesion molecules, second messengers and axonal growth. Curr Opin Neurobiol 2:595-601.

Douglas RF, Itoh K (1996) Neural cell adhesion molecules in activitydependent development and synaptic plasticity. Trend Neurosci 19:473-480.

Drapeau P, Catarsi S, Merz DC (1995) Signalling synapse formation between identified neurons. J Physiol (Paris) 89:115-123.

Fainzilber M, Smit AB, Syed NI, Wildering WC, Hermann PM, van der Schors RC, Jimenez C, Li KW, van Minnen J, Bulloch AGM, Ibanez CF, Geraerts WPM (1996) CRNF, a molluscan neurotrophic factor that interacts with the p75 neurotrophin receptor. Science 274:1540-1543.

Feng Z-P, Klumperman J, Lukowiak K, Syed NI (1996) In vitro synaptogenesis between the cell somata of identified Lymnaea neurons is independent of trophic and substrate molecules but requires protein synthesis. Soc Neurosci Abstr 22:1948.

Fuchs PA, Nicholls JG, Ready DF (1981) Membrane properties and selective connections of identified leech neurons in culture. J Physiol (Lond) 316:203-223.

Fuchs PA, Henderson LP, Nicholls JG (1992) Chemical transmission between individual Ritzius cells and sensory neurons of leech in culture. J Physiol (Lond) 323:195-210.

Fujii DK, Massoglia SL, Savion N, Gospodarowicz D (1982) Neurite outgrowth and protein synthesis by PC12 cells as a function of substratum and nerve growth factor. J Neurosci 2:1157-1175.

Funakoshi H, Belluardo N, Arenas E, Yamamoto Y, Casabona A, Persson H, Ibanez CF (1995) Muscle-derived neurotrophin-4 as an activity-dependent trophic signal for adult motor neurons. Science 268:1495-1499.

Glanzman DL, Kandel ER, Schacher S (1989) Identified target motor neuron regulates neurite outgrowth and synapse formation of Aplysia sensory neurons. Neuron 3:441-450.

Goodman CS (1994) The likeness of being: phytogenetically conserved molecular mechanisms of growth cone guidance. Cell 78:353-356.

Goodman CS (1996) Mechanisms and molecules that control growth cone guidance. Annu Rev Neurosci 19:341-377.

Goodman CS, Shatz CJ (1993) Developmental mechanisms that generate precise patterns of neuronal connectivity. Cell 72/Neuron 10 [Suppl]:77-98.

Grantyn R, KraszewskiK, Melnick I, Taschenberger H, Warton SS (1995) In vitro development of vertebrate central synapses. Perspect Dev Neurobiol 4:387-397.
Hall ZW, Sanes JR (1993) Synaptic structure and development: the neuromuscular junction. Cell 72/Neuron 10 [Suppl]:99-121.

Hawver DB, Schacher S (1993) Selective fasciculation as a mechanism for the formation of specific chemical connections between Aplysia neurons in vitro. J Neurobiol 24:368-383.

Haydon PG (1988) The formation of chemical synapses between cellcultured neuronal somata. J Neurosci 8:1032-1038.

Haydon PG, Drapeau P (1995) From contact to connection: early events during synaptogenesis. Trend Neurosci 8:196-201.

Haydon PG, Cohan CS, McCobb DP, Miller HR, Kater SB (1985) Neuron-specific growth cone properties as seen in identified neurons of Helisoma. J Neurosci Res 13:135-147.

Henderson CE (1996) Role of neurotrophic factors in neuronal development. Curr Opin Neurobiol 6:64-70.

Jessell TM, Kandel ER (1993) Synaptic transmission: a bidirectional and self-modifiable form of cell-cell communication. Cell 72/Neuron 10 [Suppl]:1-30.

Katz LC, Shatz CJ (1996) Synaptic activity and the construction of cortical circuits. Science 274:1133-1138.

Klein M (1994) Synaptic augmentation by 5-HT at rested Aplysia sensorimotor synapses: independence of action potential prolongation. Neuron 13:159-166.

Lewin GR (1996) Neurotrophins and the specifications of neuronal phenotype. Philos Trans R Soc Lond [Biol] 351:405-411.

Lindsay RM, Wiegand SJ, Allar WC, DiStefano PS (1994) Neurotrophic factors: from molecule to man. Trend Neurosci 17:182-190.

Magoski NS, Bauce LG, Syed NI, Bulloch AGM (1995) Dopaminergic transmission between identified neurons from the mollusk, Lymnaea stagnalis. J Neurobiol 74:1287-1300.

Man-Son-Hing H, Zoran MJ, Lukowiak K, Haydon PG (1989) A neuromodulator of synaptic transmission acts on the secretory apparatus as well as on ion channels. Nature 341:237-239.

McMahan UJ (1990) The synapse formation. Cold Spring Harbor Symp Quant Biol 15:407-418.

Mehrke G, Jockusch H, Faissner A, Schachner M (1984) Synapse formation and synaptic activity in mammalian nerve-muscle co-culture are not inhibited by antibodies to neural cell adhesion molecule L1. Neurosci Lett 44:235-239.

Mennerick S, Que J, Benz A, Zorumski CF (1995) Passive and synaptic properties of hippocampal neurons grown in microcultures and in mass cultures. J Neurophysiol 73:320-332.

Nelson PG, Fields RD, Yu C, Neale EA (1990) Mechanisms involved in activity-dependent synapse formation in mammalian central nervous system cell cultures. J Neurophysiol 21:138-156.

Nicholls JG, Liu Y, Payton BW, Kuffler DP (1990) The specificity of synapse formation by identified leech neurones in culture. J Exp Biol 153:141-154.

Noakes PG, Gautam M, Mudd J, Sanes JR, Merlie JP (1995) Aberrant differentiation of neuromuscular junctions in mice lacking s-laminin/ laminin $\beta 2$. Nature 374:258-262.

Ridgway RL, Syed NI, Lukowiak K, Bulloch AGM (1991) Nerve growth factor (NGF) induces sprouting of specific neurons of the snail, Lymnaea stagnalis. J Neurobiol 22:377-390.

Roubos EW, Moorer-Van Delft CM (1979) Synaptology of the central nervous system of the freshwater snail Lymnaea stagnalis (L.) with particular reference to neurosecretion. Cell Tissue Res 198:217-235.

Schacher S, Castellucci VF, Kandel ER (1988) cAMP evokes long-term facilitation in Aplysia sensory neurons that requires new protein synthesis. Science 240:1667-1669.

Spencer GE, Klumperman J, Syed NI (1997) Neurotransmitters and neurodevelopment: role of dopamine in neurite outgrowth, target selection and specific synapse formation. Perspect Dev Neurobiol, in press.

Steward O, Falk PM (1986) Protein synthetic machinery at postsynaptic sites during synaptogenesis: a quantitative study of the association between polyribosomes and developing synapses. J Neurosci $6: 412-423$.

Steward O, Davis L, Dotti C, Phillips LL, Rao A, Banker G (1988) Protein synthesis and processing in cytoplasmic microdomains beneath postsynaptic sites on CNS neurons: a mechanism for establishing and maintaining a mosaic postsynaptic receptive surface. Mol Neurobiol 2:227-261.

Stoop R, Poo M-M (1996) Synaptic modulation by neurotrophic factors: differential and synergistic effects of brain-derived neurotrophic factor and ciliary neurotrophic factor. J Neurosci 16:3256-3264. 
Syed NI, Winlow W (1991) Respiratory behaviour in the pond snail Lymnaea stagnalis. J Comp Physiol 169:557-568.

Syed NI, Bulloch AGM, Lukowiak K (1990) In vitro reconstruction of the respiratory central pattern generator $(\mathrm{CPG})$ of the mollusk Lymnaea. Science 250:282-285.

Syed NI, Richardson P, Bulloch AGM (1996) Ciliary neurotrophic factor unlike nerve growth factor supports neurite outgrowths but not synapse formation by adult Lymnaea neurons. J Neurobiol 29:293-303.

Taira E, Takaha N, Miki N (1993) Extracellular matrix proteins with neurite promoting activity and their receptors. Neurosci Res 17:1-8.

van Kesteren RE, Feng Z-P, Bulloch AGM, Syed NI, Geraerts WPM (1996) Identification of genes involved in synapse formation between identified molluscan neurons using single cell mRNA differential display. Soc Neurosci Abstr 22:1948.
Wong RG, Martel EL, Kater SB (1981) Neurite outgrowth in molluscan organ and cell cultures: the role of conditioning factor(s). J Neurosci 1:1008-1021.

Wu G-Y, Malinow R, Cline HT (1996) Maturation of a central glutamatergic synapse. Science 274:972-979.

Zhu H, Wu F, Schacher S (1994) Aplysia cell adhesion molecules and serotonin regulate sensory cell-motor cell interaction during early stages of synapses formation in vitro. J Neurosci 14:6886-6900.

Zoran MJ, Poyer JC (1996) Cellular mechanisms governing synapse formation: lessons from identified neurons in culture. Invertebr Neurosci 2:1-8.

Zoran MJ, Funte LR, Kater SB, Haydon PG (1993) Neuron-muscle contact changes presynaptic resting calcium set-point. Dev Biol 158: 163-171. 